\title{
PERANCANGAN BUKU ILUSTRASI TEMBANG DOLANAN JAWA TENGAH UNTUK ANAK USIA 5-6 TAHUN
}

\author{
Callista Chairani Wulandari ${ }^{1}$, Rizki Yantami Arumsari ${ }^{2}$ \\ 1,2 Prodi S1 Desain Komunikasi Visual, Fakultas Industri Kreatif, Universitas Telkom Bandung \\ callistacw@gmail.com¹, rizkiyantami@gmail.com²
}

\begin{abstract}
Abstrak
Indonesia merupakan negara yang terkenal akan seni dan budayanya. Setiap suku di Indonesia pasti memiliki lagu daerahnya masing-masing. Salah satu contohnya adalah tembang dolanan, yang berasal dari Jawa Tengah. Tembang dolanan merupakan sebuah lagu yang diperuntukkan bagi anak-anak, karena banyak mengajarkan tentang nilai-nilai moral yang dijunjung oleh orang Indonesia, khususnya Jawa Tengah. Namun dengan adanya lingkungan yang kurang mendukung, kini tembang dolanan sudah jarang diperdengarkan. Hal ini dibuktikan dengan penelitian yang penulis lakukan di Semarang, yang menyebutkan bahwa dari 30 anak hanya sembilan diantaranya yang tahu tentang tembang dolanan. Penelitian tersebut menunjukan bahwa tembang dolanan kini kalah pamor dengan lagu-lagu yang beredar sekarang. Padahal, seiring dengan perkembangan teknologi, kita seharusnya tetap mengajarkan kepada anak tentang nilai-nilai moral. Berdasarkan fenomena tersebut, melalui observasi, wawancara, studi kasus dan analisis, penelitian ini mengemas tembang dolanan dalam bentuk dongeng ke dalam buku ilustrasi berseri. Pada setiap buku diselipkan pula sebuah CD yang berisi tembang dolanan Jawa Tengah (Cublak-Cublak Suweng, Jaranan, Padhang Bulan, dan Gundul-Gundul Pacul) agar dapat didengarkan oleh anak-anak. Sehingga selain mendapatkan sebuah cerita dongeng, anak-anak juga mulai mengenal lagu-lagu daerah dan pesan moral yang ada di dalamnya.
\end{abstract}

Kata Kunci: buku ilustrasi, dongeng, Jawa Tengah, tembang dolanan.

\begin{abstract}
Indonesia is well-known for its cultures and arts because each region has its own culture. One of region anthem is Tembang Dolanan from Central Java that intended for kids because it contains moral values that upheld by Indonesian people especially in Central Java. But, now tembang dolanan are rarely sounded off, based on survey in Semarang that only nine out of thirty children who know about Tembang Dolanan. It shows that nowadays tembang dolanan can't compete with recent songs. Also, along with technological development, we ought to teach about moral values to our kids constantly. According to the previous case, through analysis and observation results, author consider to pack tembang dolanan into illustrated tale book series. There's a compact disk that contains tembang dolanan of Central Java (CublakCublak Suweng, Jaranan, Padhang Bulan, and Gundul-Gundul Pacul) so kids can enjoy the song. It hopefully can help kids to learn about tembang dolanan and its moral values
\end{abstract}

Keywords: illustration book, tale, Central Java, tembang dolanan. 


\section{PENDAHULUAN}

Indonesia merupakan negara dengan kekayaan adat dan budaya yang melimpah, salah satunya adalah Jawa Tengah. Menurut Jatman [1], Ada dua kaidah dasar yang dipegang dalam kehidupan masyarakat Jawa, yaitu prinsip kerukunan dan kehormatan. Prinsip tersebut juga sering digunakan sebagai landasan ketika membuat sebuah karya seni, contohnya adalah lagu (tembang). Tembang terbagi menjadi beberapa bentuk, yaitu Tembang Macapat, Tembang Gedhe, Tembang Tengahan serta Tembang Dolanan yang diperuntukan untuk anak. Tembang Dolanan mempunyai pesan moral yang tidak jauh berbeda dengan kaidah masyarakat Jawa Tengah, sehingga memiliki nilai-nilai positif yang sangat cocok apabila ditanamkan kepada anak. Namun, dengan adanya lagu-lagu pop yang bermunculan, kini tembang dolanan sudah jarang diputar dan tidak lagi dikenal.

Berdasarkan penelitian di TK Candi Baru, Semarang, Jawa Tengah pada tanggal 8 Februari 2016 terhadap anak berusia 5-6 tahun tentang tembang dolanan, ditemukan bahwa anak-anak tidak mengenal tentang tembang dolanan. Hal ini terbukti dari 30 anak hanya sembilan diantaranya yang tahu tembang dolanan dan hanya ada empat anak yang hapal lirik tembang dolanan. Ketika ditanya tentang lagu kesukaannya, 13 anak menyebut lagu Coboy Junior sebagai favorit mereka, sedangkan sisanya menjawab lagu seperti Sambalado yang dinyanyikan Ayu Ting-Ting, Armada, Al Ghazali, dan RAN. Karenanya, kita kehilangan dua kesempatan, yaitu untuk mengajarkan anak nilai moral yang terkandung di dalam lagu-lagu tersebut, serta melestarikan warisan budaya daerah.

Dalam bukunya, Brouwer et al berpendapat bahwa "Kepribadian orang merupakan ciptaan lingkungan. Kita menjadi hasil khayalan bangsa, suku, dan keluarga kita" [2]. Kepribadian seseorang merupakan hasil dari bagaimana sebuah lingkungan mengajarkan orang tersebut. Namun, adanya lagu-lagu yang kurang mendukung menyebabkan adanya penyimpangan perilaku pada anak. Padahal, dengan majunya teknologi, seharusnya kita lebih dapat memberikan calon penerus bangsa nilai-nilai moral dalam pembelajaran mereka. Selain itu, peran orang tua dan media pembelajaran juga menjadi salah satu faktor penentu dalam hal ini.

Media pembelajaran dibagi menjadi tiga, yaitu auditif, visual, serta audiovisual [3]. Sedangkan, media yang umum ditemui di masyarakat adalah visual dan audio seperti buku dan musik. Musik yang digunakan biasanya melibatkan gerak tubuh sehingga selain belajar, anak juga melatih gerak motorik mereka. Sedangkan buku, khususnya untuk anak-anak, sering menggunakan ilustrasi yang menceritakan kegiatan seharihari, sejarah, maupun mitos yang umumnya dikemas dalam bentuk dongeng dengan warna yang cerah serta penuturan yang sederhana sehingga dapat dipahami oleh anak-anak.

Berdasarkan fenomena tersebut, penelitian ini akan mengemas tembang dolanan dalam bentuk dongeng ke dalam buku ilustrasi, sehingga selain mendapatkan sebuah cerita dongeng, anak-anak juga dapat memahami pesan moral dari lagu tersebut. Hal 
ini dilakukan karena masih jarangnya buku anak yang mengangkat tema tembang dolanan. Pengumpulan data yang dilakukan adalah dengan cara melakukan observasi terhadap 5 buku ilustrasi anak untuk dijadikan acuan dalam mendesain, wawancara secara terstruktur kepada ahli buku anak, psikologi anak, dan dosen tembang, serta wawancara tidak terstruktur kepada anak usia 5-6 tahun. Selain itu, penulis juga mengumpulkan data melalui studi pustaka dan analisis matriks.

Buku anak harus memiliki pertimbangan moral, pantang menjustifikasi, tidak vulgar, dan yakin bahwa cerita dapat memberi sudut pandang kepada pembacanya. Sebab di dalam buku anak, misi yang dibawa bukan hanya pesan moral, namun juga pengenalan terhadap suatu masalah dan bagaimana cara mengatasinya. Setelah memahami rambu-rambu tersebut, barulah menentukan genre cerita. Kebanyakan buku anak adalah kisah fiksi dan fantasi, walaupun ada juga yang kisah nyata. Tujuannya sama, yaitu untuk menambah pengetahuan dan sekaligus menjadi rekreasi anak sehingga anak tidak lagi menganggap membaca sebagai kegiatan yang membosankan [4].

Dalam pembuatan buku anak, perlu diperhatikan unsur-unsur yang bersangkutan, yaitu:

a. Tema; Tema sebuah cerita adalah makna yang tersembunyi yang mencakup pesan moral dan amanat. Tema bagi cerita anak harus baik serta mampu menerjemahkan kebenaran.

b. Tokoh; Tokoh adalah "pemain" dalam sebuah cerita. Tokoh yang digambarkan secara baik dapat menjadi teman, tokoh identifikasi, atau bahkan menjadi orang tua sementara bagi pembaca.

c. Latar; Setting tempat harus disesuaikan dengan daya pikir anak seperti yang ada dikeliling anak sehingga anak dengan mudah memahaminya.

d. Gaya bahasa; Pada buku anak, kalimat dalam cerita anak-anak harus lugas, langsung pada inti dan tidak menggunakan kalimat tunggal.

e. Alur; Pada buku anak, alur biasanya dirancang secara kronologis, yang menaungi periode tertentu dan menghubungkan peristiwa-peristiwa dalam periode tertentu.

f. Amanat; Cerita anak harus mengandung pesan moral yang baik seperti pesan seperti kasih sayang, kepedulian, kejujuran,, ketegaran, kesabaran, kepercayaan sehingga akan membentuk karakter dan pribadi anak. [5]

Sedangkan unsur desain yang perlu diperhatikan adalah ilustrasi, layout, warna, dan tipografi. Ilustrasi dalam buku anak berguna untuk memberikan gambaran tentang tokoh atau karakter dalam cerita. Ilustrasi secara harfiah berarti gambar yang dipergunakan untuk menerangkan atau mengisi sesuatu [6]. Layout yang digunakan dalam buku anak biasanya menggunakan style Juvenille dengan kesan meriah dan gambar yang menyebar. Warna pada buku anak menggunakan warna-warna cerah, karena warna juga dapat mempengaruhi kondisi emosional anak. Tipografi yang digunakan pada buku anak cenderung sederhana dengan ketebalan stroke yang tidak terlalu jauh sehingga memudahkan anak dalam fokus membaca. 


\section{METODE PENELITIAN}

Metode yang digunakan dalam penelitian ini adalah:

a. Observasi; meneliti lima buku anak lainnya, untuk dijadikan pembanding. Lima buku yang menjadi acuan adalah buku Ups, Licin!, Nami Sakit Cacar, Ollie Ingin ke Bulan, Petualangan Froggy dan Nila, dan Rumah Kecil di Padang Rumput.

b. Wawancara, yang dibagi menjadi:

1. Terstruktur; yang dilakukan kepada tiga sumber, yang pertama yaitu Bapak Darsono S.R, M.Hum selaku dosen tembang di Institut Seni Indonesia, Solo, Bapak Ali Muakhir, seorang Ahli Buku Anak, dan Ibu Nirta Fitri M. Psi selaku psikolog anak.

2. Tidak Terstruktur; yang dilakukan kepada 50 anak usia 5-6 tahun secara acak di area toko buku dan game center.

c. Studi Pustaka; menggunakan buku sebagai studi pustaka, diantaranya ialah buku Pengantar Desain Komunikasi Visual dan Psikologi Jawa. [1] [6]

d. Analisis Matriks; penyusunan data dengan menggunakan matriks sehingga lebih mudah untuk memaparkan, menganalisis serta membaca kesimpulan data.

\section{HASIL DAN PEMBAHASAN}

Produk yang dihasilkan merupakan buku ilustrasi berseri tembang dolanan. Buku ilustrasi ini menggunakan cover hardbook dengan art paper 260 sebagai kertas isinya. Didalamnya, terdapat empat buah buku yang masing-masing berisi satu tembang dolanan (Cublak-Cublak Suweng, Jaranan, Gundul-Gundul Pacul, dan Padhang Bulan), yang menceritakan tentang makna dari tembang-tembang tersebut. Selain itu, terdapat pula satu buah CD berisi empat tembang dolanan, sepuluh stiker, serta satu tas serut bergambar tokoh dalam buku tersebut.

Buku yang dibuat secara utuh adalah Buku Tembang Dolanan Cublak-Cublak Suweng, sedangkan tiga buku lainnya hanya sebatas dummy, dan dibuat bagian covernya saja. Cublak-Cublak Suweng sendiri mempunyai makna 'untuk mendapatkan kebahagiaan sejati, orang harus memiliki hati nurani serta mengosongkan diri dari keserakahan duniawi'. Khalayak Sasaran yang dituju oleh buku ini ada dua, yaitu primer dan sekunder. Sasaran primer merupakan anak berusia 5-6 tahun yang berada di Taman Kanak-Kanak yang berdomisili di Jawa Tengah, khususnya Semarang. Sedangkan pada sasaran sekunder adalah orang tua dari sasaran primer. Pencetakan buku ini bekerjasama dengan PT. Tiga Serangkai, penerbit buku yang berlokasi di Jalan Dr. Supomo nomor 23, Solo yang menyediakan buku sekolah dan umum yang didistribusikan oleh jaringan toko buku modern maupun tradisional.

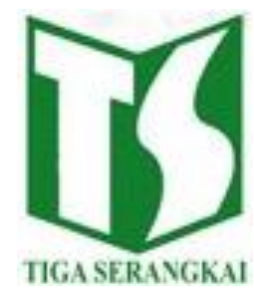

Gambar 1. Logo Tiga Serangkai

[Sumber: www.for-indonesia.com, 2016] 
Uraian hasil pengumpulan data dan analisis dirangkum dalam tabel dibawah ini:

Tabel 1. Matriks Uraian Hasil Pengumpulan Data dan Analisis

[Sumber: Callista \& Rizki, 2016]

\begin{tabular}{|c|c|}
\hline Observasi & $\begin{array}{l}\text { Buku ilustrasi anak mempunyai ciri dengan karakter utama yaitu } \\
\text { karakter anak, atau juga karakter binatang. Tipografi cenderung } \\
\text { tegas, tebal namun tidak lancip dan mudah dibaca. Warna yang } \\
\text { digunakan beragam, namun mempunyai beberapa warna yang } \\
\text { dominan pada setiap halamannya. Layout yang digunakan } \\
\text { cenderung mempunyai banyak gambar, dengan kata-kata yang } \\
\text { cukup minim, dan berada di bagian atas ataupun bawah buku. }\end{array}$ \\
\hline Studi Pustaka & $\begin{array}{l}\text { Ilustrasi pada buku anak mampu memberikan gambaran serta } \\
\text { memvisualisasikan keadaan serta membuat anak membantu } \\
\text { berimajinasi. Sedangkan warna juga mempunyai peranan yang } \\
\text { penting dalam buku anak karena dapat menghidupkan suasana, } \\
\text { dan memainkan emosi sehingga anak dapat lebih } \\
\text { memahaminya. Tipografi yang digunakan biasanya bersifat tebal } \\
\text { dan lurus (tidak lancip maupun berdekoratif) sehingga anak } \\
\text { mampu membacanya dengan cermat. }\end{array}$ \\
\hline $\begin{array}{l}\text { Wawancara Tidak } \\
\text { Terstruktur }\end{array}$ & $\begin{array}{l}\text { Dari wawancara tidak terstruktur, dapat disimpulkan bahwa } \\
\text { anak-anak menyukai buku tentang agama, dongeng dan } \\
\text { permainan dibandingkan dengan berhitung dan menulis serta } \\
\text { kegiatan mandiri. Setengah dari responden menyebutkan } \\
\text { bahwa mereka menyukai buku yang mereka pilih sendiri karena } \\
\text { adanya banyak warna dan juga gambar. }\end{array}$ \\
\hline $\begin{array}{l}\text { Wawancara } \\
\text { Terstruktur }\end{array}$ & $\begin{array}{l}\text { Tembang dolanan dahulu diciptakan oleh para wali sebagai cara } \\
\text { berdakwah yang ditujukan untuk mengajak masyarakat Jawa } \\
\text { untuk mendalami ajaran Islam. Cublak-Cublak Suweng } \\
\text { mempunyai makna bahwa kebahagiaan sejati tidaklah sukar } \\
\text { untuk dicari, yang patut dijadikan bahan ajaran untuk anak. } \\
\text { Pada usia 5-6 tahun segi kognitif anak sedang berkembang, } \\
\text { sehingga tidak dapat membedakan mana baik dan buruk. } \\
\text { Karena perkembangan kognitif terbentuk dari pengetahuan } \\
\text { sosial, maka perlu adanya rangkulan dari lingkungan yang } \\
\text { berfungsi sebagai penyaring. Sedangkan media pembelajaran } \\
\text { yang cocok untuk usia } 5-6 \text { tahun adalah benda yang konkret, } \\
\text { serta multisensory sehingga proses pengingat dan pemahaman } \\
\text { lebih baik. Diharapkan ada alat peraga visual serta dapat } \\
\text { dipegang karena mereka belum mempunyai tingkat } \\
\text { pemahaman abstrak, Buku yang cocok untuk anak usia ini } \\
\text { adalah buku dengan alat peraga seperti puppet, pop up, gambar } \\
\text { yang bergerak. Selain itu usahakan untuk lebih banyak } \\
\text { menggunakan gambar, dengan tulisan maksimal } 5 \text { kalimat pada } \\
\text { satu halaman. Lebih bagus lagi jika sang pencerita langsung } \\
\text { memperagakan cerita tersebut kepada anak-anak. }\end{array}$ \\
\hline
\end{tabular}




\begin{tabular}{|c|c|}
\hline & $\begin{array}{l}\text { Selain itu, buku sebaiknya tidak lebih dari } 32 \text { halaman, dengan } \\
\text { bahan yang tidak mudah sobek, tahan air, kuat untuk diduduki, } \\
\text { terinjak dan sebagainya (boardbook). Pada warna, usahakan } \\
\text { memainkan warna-warna dasar, dengan ilustrasi yang clear } \\
\text { serta tipografi yang mudah dibaca (tebal, tidak keriting dan tidak } \\
\text { lancip). }\end{array}$ \\
\hline $\begin{array}{l}\text { Matriks } \\
\text { Perbandingan }\end{array}$ & $\begin{array}{l}\text { Dari hasil analisa pada lima buku yang dibandingkan, dapat } \\
\text { disimpulkan bahwa buku anak yang banyak dijumpai memiliki } \\
\text { ilustrasi yang memperkenalkan dua karakter atau lebih (utama } \\
\text { dan pendukung), serta latar belakang dan elemen visual } \\
\text { pendukung yang saling berhubungan. Warna yang banyak } \\
\text { digunakan merupakan warna seperti biru, merah, kuning, merah } \\
\text { muda, dan ceria tergantung dari dimana latar belakang cerita } \\
\text { tersebut diambil (contoh: jika temanya adalah kamar mandi } \\
\text { akan ditonjolkan warna biru, ketika latar belakang ada di padang } \\
\text { rumput maka menonjolkan warna kuning, hijau untuk padang } \\
\text { rumput dan biru, putih untuk langit). Font yang digunakan } \\
\text { merupakan Sans Serif yang terlihat tidak kaku dan formal, serta } \\
\text { font Miscellaneous yang telah dimodif agar sesuai untuk anak. } \\
\text { Pada Layout, menggunakan style Juvenille yang memasang } \\
\text { gambar secara menyebar (menyeluruh) dengan teks yang } \\
\text { mempunyai jarak antar karakter dan mengikuti gambar. }\end{array}$ \\
\hline
\end{tabular}

Dalam perancangan konsep terbagi menjadi empat bagian yaitu konsep pesan, konsep kreatif, konsep media, dan konsep visual. Penjelasannya adalah sebagai berikut:

a. Konsep Pesan

Konsep pesan yang akan disampaikan dalam buku seri tembang dolanan CublakCublak Suweng Bersama Bimo dan Ibu ini adalah untuk mengajarkan bahwa kebahagiaan tidak hanya diukur dari harta maupun tahta. Jika kita mau melihat sekeliling kita, banyak kebahagiaan yang sesungguhnya kita miliki seperti kesehatan, kasih sayang dari keluarga serta sahabat dan orang-orang terdekat. Efek yang diharapkan muncul adalah timbulnya kesadaran pada diri anak untuk bisa lebih menghormati diri sendiri, keluarga maupun orang lain serta menghargai hal-hal yang telah ia miliki walaupun mungkin murah harganya.

b. Konsep Kreatif

Konsep kreatif pada buku ini adalah melakukan pendekatan dengan karakter anak laki-laki berumur 5 tahun yang mempunyai keingintahuan yang sangat tinggi, mirip dengan target sasaran, dengan alur cerita yang berjalan maju dengan sehingga mudah dipahami oleh anak. Disini karakter anak laki-laki tersebut ditunjang dengan karakter dari ibu sang anak, yang menjelaskan tentang keingintahuan anak terhadap para pemain yang sedang memperagakan permainan Cublak-Cublak Suweng serta lirik lagu yang mereka nyanyikan. 
Perancangan buku ini menggunakan sentuhan adat Jawa dengan penggunakan kain batik maupun pakaian adat jawa pada ceritanya, warna-warna yang terang (setting cerita adalah pagi hari), tipografi yang mudah dibaca oleh anak serta penambahan interaksi Lift the Flap diharapkan mampu menambah minat anak dalam mengikuti alur cerita. Selain itu dimasukan pula CD berisi tembang dolanan pada buku sehingga dapat didengarkan bersama anak dan orang tua.

c. Konsep Media

Media pada perancangan ini dibuat dalam bentuk seri Tembang Dolanan, yang terdiri dari empat buku. Yang pertama merupakan buku cerita ilustrasi tentang tembang dolanan Cublak-Cublak Suweng yang mengajarkan tentang kebahagiaan yang sejati, kemudian ada tiga tembang dolanan lainnya yang juga mempunyai makna tersendiri. Namun yang dicetak lengkap adalah buku cerita ilustrasi tembang dolanan Cublak-Cublak Suweng, sedangkan tiga yang lain hanya berupa dummy.

Pemilihan buku sebagai media dikarenakan buku merupakan media yang konkret serta dapat disentuh secara langsung oleh anak. Terlebih, buku lebih sehat digunakan oleh anak dibandingkan dengan gadget. Beberapa hal yang dipertimbangkan dalam konsep media adalah:

1. Teknik Gambar; Teknik gambar menggunakan sketsa manual yang kemudian di tracing ke media digital dengan Adobe Photoshop dan Illustrator.

2. Halaman; Halaman yang akan dibuat sebanyak 32 halaman, untuk mencegah anak dari rasa bosan.

3. Kertas; Pada bagian cover menggunakan yellow board yang dilapisi dengan art paper dan dilaminasi dingin. Sedangkan pada bagian dalam menggunakan kertas art paper $260 \mathrm{gr}$.

4. Ukuran; Ukuran buku yang akan dirancang yaitu $20 \times 20 \mathrm{~cm}$, mempertimbangkan banyaknya buku untuk anak pada usia 5-6 tahun menggunakan ukuran 20 hingga $30 \mathrm{~cm}$.

5. Storyline; Judul buku perancangan ini adalah "Bimo dan Cublak Suweng". Berikut merupakan storyline dari perancangan buku ini:

a) Exposition (Pengenalan)

Mengenalkan dua karakter utama (Bimo dan Ibunya) yang sedang berjalanjalan ke Festival Kebudayaan Jawa. Bimo dan Ibunya melihat banyak sekali orang-orang dengan pakaian adat Jawa Tengah, mainan tradisional dan makanan khas Jawa Tengah.

b) Conflication (Konflik)

Bimo mendengarkan orang-orang berkumpul ramai-ramai. Karena rasa penasaran yang tinggi, Bimo datang menghampiri dan melihat lima orang yang sedang duduk sambil bernyanyi mengelilingi satu orang yang sedang tidur duduk menghadap tanah.

c) Turning Plot (Klimaks)

Bimo panik karena mengira mereka sedang bertengkar, lalu memanggil ibunya. Ketika ibunya datang, Ibu Bimo malah tertawa dan meminta ijn kepada mereka. Bimo bingung karena sang ibu malah menyuruhnya untuk 
bergabung. Bimo yang tidak tahu apa-apa hanya bertanya ke sang Ibu tentang apa yang dilakukan oleh orang-orang tersebut.

d) Ending (Penyelesaian Masalah)

Ibunya dengan sabar menjelaskan tentang permainan Cublak-Cublak Suweng dan mengajari Bimo lirik lagunya satu per satu. Akhirnya Bimo tahu tentang lagu dan permainan Cublak-Cublak Suweng serta maknanya, dan tidak sabar mengajak teman-temannya di rumah untuk bermain, menyanyikan lagu Cublak-Cublak Suweng.

d. Konsep Visual

Konsep visual yang ada dalam buku dirancang dengan menonjolkan ilustrasi dan permainan warna, dengan dibantu dengan adanya halaman interaktif yang diharapkan mampu menarik minat anak sehingga lebih tertarik untuk membacanya. Teknik perwarnaan secara digital dengan pemilihan warna yang ceria dan riang. Penggayaan gambar yang digunakan adalah vektor dengan warna yang kuat.

Berikut penjelasan tentang gaya gambar, pewarnaan, dan teknik puppet yang dirancang:

1. Tipografi

Tipografi yang akan digunakan merupakan tipografi dengan jenis font Chalkboard, karena tidak menggunakan serif dan mempunyai bagian stroke yang bedanya tidak terlalu besar sehingga tidak terkesan formal atau kaku dan mudah dibaca.

2. Warna

Konsep perancangan warna yang diterapkan pada Buku llustrasi seri Tembang Dolanan Bimo dan Cublak Suweng menggunakan warna cokelat pada karakter. Pada latar belakang menggunakan warna-warna cerah, mengikuti setting latar yaitu pagi hari dan di luar ruangan.

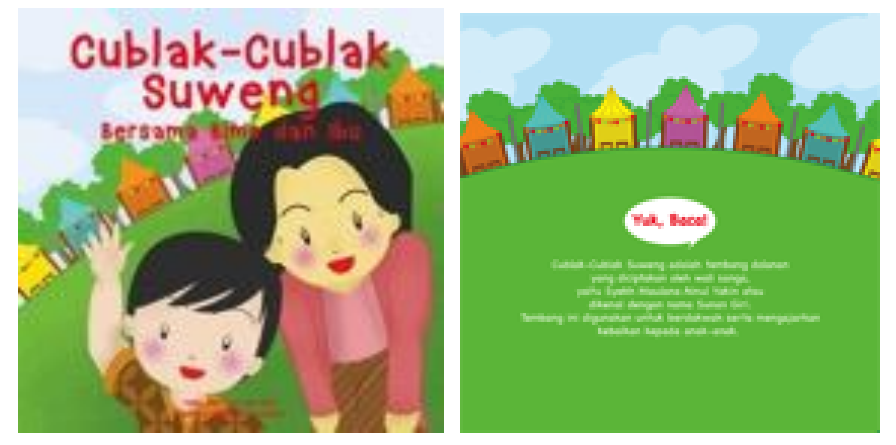

Gambar 2. Penggunaan warna cerah dalam buku ilustrasi Cublak-Cublak Suweng [Sumber: Callista \& Rizki, 2016]

3. Gaya Visual

Buku yang digunakan sebagai referensi adalah Ups, Licin! dengan gaya vektor serta pewarnaan yang ceria. Pada karakter, akan menonjolkan warna-warna pada batik yang biasa ada di Jawa Tengah, yaitu bernuansa cokelat. Pada 
karakter Bimo, motif batik yang digunakan adalah batik kawung, sedangkan pada karakter Ibu, motif yang digunakan adalah batik parang lereng.

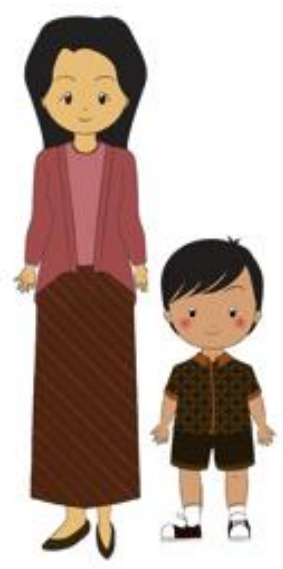

Gambar 3. Penggunaan motif batik pada karakter Bimo dan Ibu [Sumber: Callista \& Rizki, 2016]

4. Teknik Lift the Flap

Menggunakan teknik Lift the Flap pada beberapa objek gambar di buku ilustrasi, namun tidak seluruhnya, hanya pada 3 halaman yaitu halaman enam, halaman sembilan, dan halaman sepuluh.

Hasil perancangan isi buku adalah sebagai berikut:
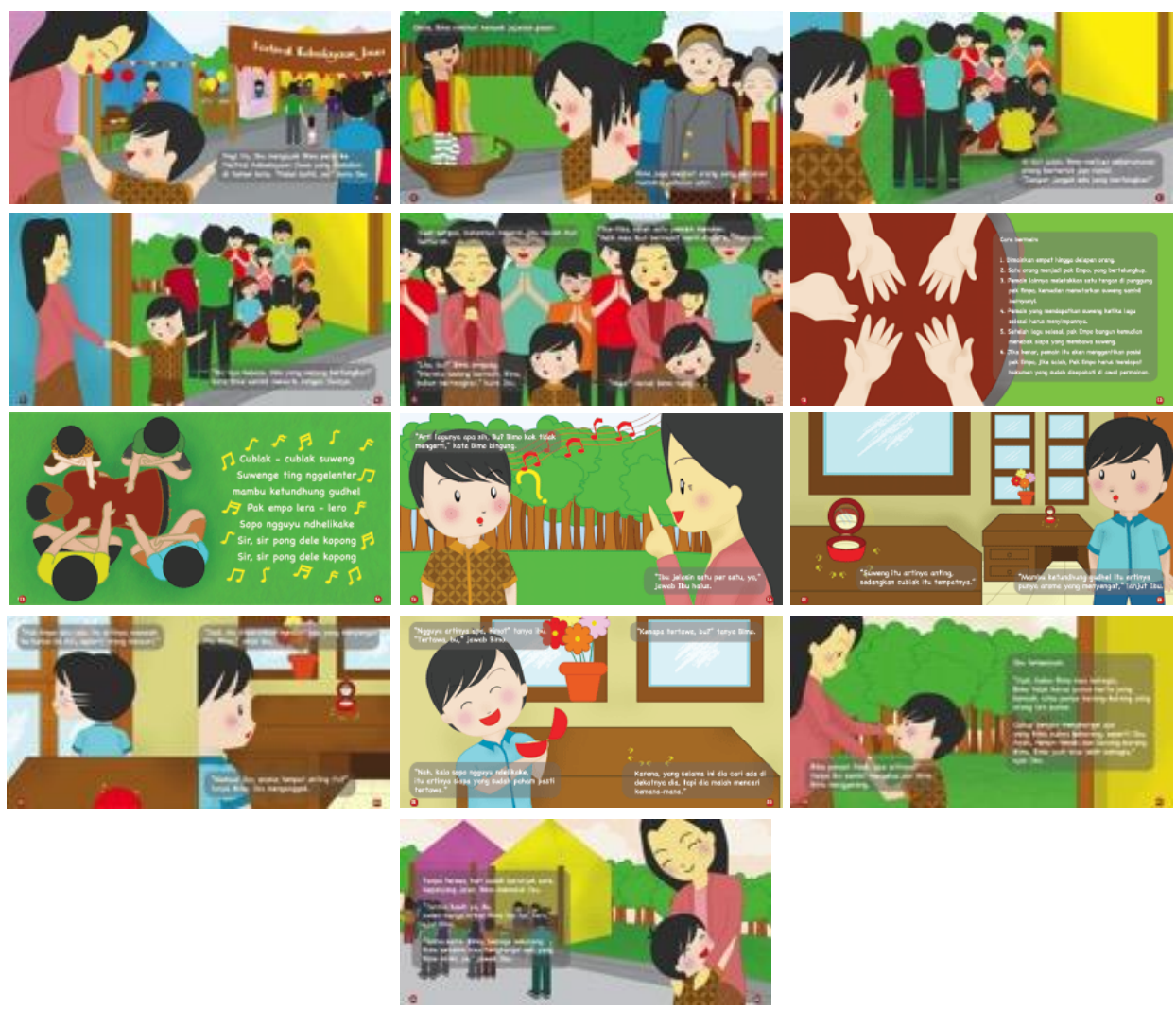

Gambar 4. Isi buku ilustrasi Cublak-Cublak Suweng

[Sumber: Callista \& Rizki, 2016] 


\section{KESIMPULAN}

Buku ilustrasi tembang dolanan Jawa Tengah untuk anak usia 5-6 tahun ini merupakan sebuah media berbentuk buku cerita bergambar yang digunakan untuk bercerita dan berinteraksi sekaligus memperkenalkan kepada anak tentang tembang dolanan baik makna maupun lirik dan lagunya. Buku dirancang berseri, dengan empat lagu yang mempunyai nilai moral berbeda-beda. Perancangan dengan model buku cerita ilustrasi serta adanya CD berisi empat tembang dolanan diharapkan menambah daya tarik anak dalam membaca maupun mempelajari tembang dolanan. Selain dua hal diatas, buku juga dilengkapi dengan adanya beberapa halaman interaktif yang dapat dilipat dan dibuka.

Dengan adanya buku cerita ilustrasi ini, diharapkan dapat membantu para orang serta guru maupun pihak yang berhubungan agar mampu mengajari anak-anak tentang tembang dolanan, nilai-nilai yang terdapat di dalamnya, serta dapat melestarikan lagulagu warisan daerah yang kini sudah jarang diperdengarkan lagi. Selain itu, adapula saran yang ditunjukan, kepada:

1. Orang Tua

a. Diharapkan dapat memberikan waktu kepada anaknya untuk bercerita maupun mendengarkan cerita sang anak;

b. Memperkenalkan budaya daerah sendiri sehingga memicu anak untuk suka, atau setidaknya tertarik untuk mempelajari maupun menikmatinya.

2. Instansi Pemerintahan

a. Dinas Kebudayaan dan Pariwisata, khususnya bagian Seni dan Budaya diharapkan mampu memberikan kontribusi lebih, melalui event-event yang mengusung tema kebudayaan;

b. Kegiatan dikemas dalam bentuk sedemikian rupa sehingga tidak membosankan bagi anak-anak.

\section{DAFTAR PUSTAKA}

[1] Jatman, Darmanto. 2011. Psikologi Jawa. Cetakan Kedua. Yogyakarta: Yayasan Kayoman.

[2] Brouwer, M.A.W., et al. 1989. Kepribadian dan Perubahannya. Edisi Kedua. Jakarta: PT. Gramedia.

[3] Sadiman, Arief S., dkk. 1993. Media Pendidikan. Jakarta: PT. Raja Grafindo Persada.

[4] Nilawaty, Cheta. 2016. Menulis Buku Anak, Apa Saja yang Harus Diperhatikan?. Diakses pada www.tempo.co (3 April 2016, 14.02 WIB).

[5] Sarumpaet, Riris K.T. 2013. "Struktur Bacaan Anak" dalam Teknik Menulis Cerita Anak. Yogyakarta: Pink Books, Pusbuk, dan Taman Melati.

[6] Kusrianto, Adi. 2009. Pengantar Desain Komunikasi Visual. Yogyakarta: Penerbit Andi. 